\title{
Particle Removal Characteristics of a High-velocity Electrostatic Mist Eliminator
}

\author{
Jin-Seon Kim ${ }^{1,2}$, Hak-Joon Kim ${ }^{1,2}$, Bangwoo Han ${ }^{1,2}$, Sangrin Lee ${ }^{3}$, Jinwoon Lee ${ }^{3}$, \\ Sangchul Moon ${ }^{3}$, Yong-Jin Kim ${ }^{*}$ \\ ${ }^{1}$ Environmental System Research Division, Korea Institute of Machinery and Materials, Daejeon 34103, Korea \\ ${ }^{2}$ Environmental and Energy Mechanical Engineering, University of Science and Technology, Daejeon 34113, Korea \\ ${ }^{3}$ Energy and Environment Technology Development Team, Doosan Heavy Industries \& Construction Co., Ltd., \\ Gyeongsangnam-do 51711, Korea
}

\begin{abstract}
In this study, we developed a flat plate-type wet electrostatic precipitator that generates stable corona discharge compared to wire-type discharge electrodes. Particle removal efficiencies were compared among differing shapes of the discharge electrode, including varying horizontal and vertical distances between spiked edges, and varying the height of the discharge pin support. When the horizontal distance between spiked edges was increased to $36 \mathrm{~mm}$, the vertical distance between spiked edges increased to $54 \mathrm{~mm}$, and when the height of the discharge pin support was increased to $76 \mathrm{~mm}$, the removal efficiency of $\mathrm{PM}_{10}$ was maintained at approximately $60.0 \%$. Furthermore, the removal efficiency of particles over $5 \mu \mathrm{m}$ was about $80 \%$ or greater. When the flow rate was $4 \mathrm{~m} \mathrm{~s}^{-1}$, the gap between collection plates was $60 \mathrm{~mm}$, and $-14 \mathrm{kV}$ was applied to the discharge electrode. The particle removal efficiency of the flat plate-type electrostatic precipitator was maintained when the horizontal and vertical distances between spiked edges and the height of the discharge pin support were below threshold levels. Those variables may be important factors for designing the shape of the discharge electrode. Therefore, when designing electrostatic precipitators with multiple channels, the discharge electrode weight and processing costs must be considered when determining the optimal horizontal and vertical distances between spiked edges and the height of discharge pin support.
\end{abstract}

Keywords: Mist eliminator; Electrostatic precipitator; Discharge electrode; Corona discharge.

\section{INTRODUCTION}

With rapid economic growth in Northeast Asia, large amounts of air pollutants are being emitted, resulting in high concentrations of $\mathrm{PM}_{2.5}$ (Choi and Kim, 2018). Fang et al. (2018) observed $\mathrm{PM}_{2.5}$ concentrations in Asian countries including China, Mongolia, Hong Kong, Taiwan, Korea, Japan, and India from 1994 to 2014. They found that the $\mathrm{PM}_{2.5}$ concentration in China has risen the fastest among Asian countries over the last 20 years, although $\mathrm{PM}_{2.5}$ concentrations have increased significantly in all countries tested. In particular, the annual average $\mathrm{PM}_{2.5}$ concentration

\footnotetext{
${ }^{*}$ Corresponding author.

Tel.: 82-42-868-7475; Fax: 82-42-868-7284

E-mail address: yjkim@kimm.re.kr
}

This article is an English version of "Particle removal characteristics of high-velocity electrostatic mist eliminator [Korean]" published in Particle and Aerosol Research in December 2018. for the entire country of Korea, as announced by the Ministry of Environment, was $23 \mu \mathrm{g} \mathrm{m}^{-3}$ in 2018 , more than double the $10 \mu \mathrm{g} \mathrm{m}^{-3}$ level suggested by the World Health Organization (WHO). Prolonged exposure to fine particulates such as $\mathrm{PM}_{2.5}$ increases the incidence of pneumonia and lung cancer, decreases pulmonary function, stimulates blood vessels, and increases the risk of death from cardiovascular diseases such as myocardial infraction and heart failure (Castanas and Kampa, 2007). Therefore, air pollutant emissions control and abatement techniques are necessary for reducing $\mathrm{PM}_{2.5}$ concentrations. According to the comprehensive measures for fine particulate management adopted in 2017, domestic fine particulate emission sources nationwide include the workplace $(38 \%)$, construction machinery and ships $(16 \%)$, and power plants $(15 \%)$. Fine particulate emission sources in the Seoul metropolitan area include diesel vehicles $(23 \%)$, construction machinery (16\%), and workplaces (14\%). Reducing fine particulate emissions from the workplace is essential. Short-, medium-, and long-term measures to reduce fine particulate emission sources in the workplace, and emission allowance standards for large-scale industrial plants (steel manufacturing, petroleum refining, cement manufacturing, etc.) will be strengthened, and penalties 
imposed for excessive nitrogen oxide emissions. Thus, the installation and maintenance of high-performance exhaust gas cleaning facilities at each work site will be required.

The conventional mist eliminator (ME) is widely applied for air pollution control in steel manufacturing, vehicle engines, and flue-gas desulfurization (FGD) at coal-fired power plants. The ME is usually designed with aligned plates that have regular gaps for multiple narrow channels and hooks to remove particles. The principle of particle removal by $\mathrm{ME}$ is collision due to inertial force. When a particle or droplet contained in the gas passes through the narrow channels between plates, those particles or droplets with high inertial force collide with the wall because they cannot follow the streamline as it repeatedly changes. Thus, collected particles or droplets collect on the wall to form a liquid film, which is drained by gravity (James and Wang, 1998; Melaaen and Jøsang, 2002; Azzopardi et al., 2003; Kulasekharan et al., 2013; Fan et al., 2015; Hamedi Estakhrsar et al., 2016). Due to this removal mechanism, existing ME do not effectively remove mists if the flow velocity is low or particle size is small; increasing the particle size or flow velocity increases the mist removal efficiency (Jiang et al., 2017). Fine mist particles with diameters of $10 \mu \mathrm{m}$ or smaller are particularly difficult to capture and remove with existing ME types (Banitabaei et al., 2012). The wet electrostatic precipitator (WESP) is widely used in various industrial fields such as waste incineration plants and steel manufacturing, as it offers a simple method for collecting fine particles, high collection efficiency, and low pressure drop (Jo and Park, 2013; Guerra and Oliveira, 2018). However, the conventional WESP has limited application due to problems such as reduced flow rate and large equipment size.

In this study, a new type of electrostatic mist eliminator (EME) was developed that minimizes the space needed for installation and maximizes corona discharge. To achieve the advantages of space-efficient utilization from the 1-stage electrostatic precipitator (ESP) and high collection efficiency from the 2-stage ESP, we designed a flat plate-type discharge electrode that can generate stable corona discharge (Jaworek et al., 2018) by combining the high-voltage plate in the collection stage with the discharge electrode.

\section{METHODS}

Fig. 1 shows a schematic diagram of the experimental apparatus, which is a flat plate-type WESP with one channel. It is capable of replacing various types of discharge electrodes, as shown in Fig. 2, which were tested to compare particle removal performance with variations in the flow rate, gap between collection electrodes, and shape of discharge electrodes. The collection electrodes were made of stainless steel with a thickness of $4 \mathrm{~mm}$ and length and width of $500 \mathrm{~mm}$. The discharge electrode, which is located between the two collection electrodes, was made of stainless steel with a thickness of $2 \mathrm{~mm}$, a width of $396 \mathrm{~mm}$, and a length of $457 \mathrm{~mm}$. The oil mist (Tapping Oil, ST-501, E-Le Industry Co., Ltd., Korea) used in this study is suitable for comparing particle removal efficiency as it is not charged by friction between the air and particles during the process of particle generation. To compare particle collection performance at different flow rates and different sized gaps between collection electrodes, two nebulizers (8900-7-50, Salter Labs, USA) were used to generate oil mist. Compressed air was supplied at 2 bar to nebulizers by a mass flow controller (TN-280SAV, Celerity Inc., USA) at 4.5 to 6.0 $\mathrm{L} \mathrm{min}^{-1}$ as the flow rate of the ESP increased to maintain similar inlet concentration conditions. To compare different discharge electrode shapes, compressed air was supplied at 2 bar to two nebulizers by a mass controller at $4.5 \mathrm{~L} \mathrm{~min}^{-1}$. A circular plate with a diameter of $90 \mathrm{~mm}$ was installed 300 $\mathrm{mm}$ from the outlet of the nebulizer to facilitate mist mixing during oil mist generation and to fundamentally block the inflow of larger particles at high speed. The flow rate of the ESP was controlled using a centrifugal fan (DATF-2.5\#, DONG-A PUNG REOK Co., Ltd., Korea), and the flow rate in the duct was measured by connecting a 16-mm vane-type probe to a digital temperature and humidity meter (Testo 480, Testo SE \& Co. KGaA, Germany). The internal flow rate of the ESP was varied between 2 and $5 \mathrm{~m} \mathrm{~s}^{-1}$ during the experiment according to the flow rate, and the internal flow rate was fixed at $4 \mathrm{~m} \mathrm{~s}^{-1}$ to evaluate particle collection performance according to the shape of the discharge electrode. Corona discharge and particle collection were achieved by applying voltage to the ESP using a DC high-voltage generator ( $\max -30 \mathrm{kV} / 10 \mathrm{~mA}$; Korea Switching, Korea), and the mass concentration distribution by particle size was measured using a portable laser aerosol spectrometer (OPC; Model 1.109, Grimm Aerosol Technik GmbH, Germany) connected to the isokinetic sampling probe (\#1.152 isokinetic stainless steel sampling probe; Grimm Aerosol Technik GmbH, Germany).

Fig. 2 shows the basic shape of the discharge electrode used in the experiment. It contains eight horizontal rows with sawtooth edges spaced $46 \mathrm{~mm}$ apart and a support with a width of $12 \mathrm{~mm}$ in the longitudinal direction along the middle of the discharge electrode. The sawtooth-shaped discharge pins, which generate corona discharge with the application of high voltage, are located along each row in the shape of a triangle with a $7-\mathrm{mm}$ base and $8 \mathrm{~mm}$ in height. The horizontal distance between each discharge pin is 12 $\mathrm{mm}$, the longitudinal distance is $30 \mathrm{~mm}$, and the height of the support for the discharge pin is $15 \mathrm{~mm}$. In this study, we experimentally changed the horizontal and longitudinal distances between sawtooth discharge pins and the height of the support for the discharge pins, as shown in Fig. 3, to determine the optimal discharge electrode shape.

For the horizontal spacing of discharge pins of 12, 24, 36, $72,81,144 \mathrm{~mm}$, the particle removal efficiencies of seven discharge electrodes were compared, including a discharge electrode without a discharge pin. To determine the effects of longitudinal spacing of discharge pins, while incrementally reducing the number of supports for the discharge pins and maintaining equal spacing, the longitudinal spacing of the discharge pins varied from 30 to $40,54,76,111$, and $183 \mathrm{~mm}$. For these tests, the horizontal distance between discharge pins was fixed at $36 \mathrm{~mm}$. Likewise, to test changes in the height of the support for the discharge pins, when the horizontal spacing of discharge pins was $36 \mathrm{~mm}$, the longitudinal spacing of discharge pins was fixed at $30 \mathrm{~mm}$; incrementally 


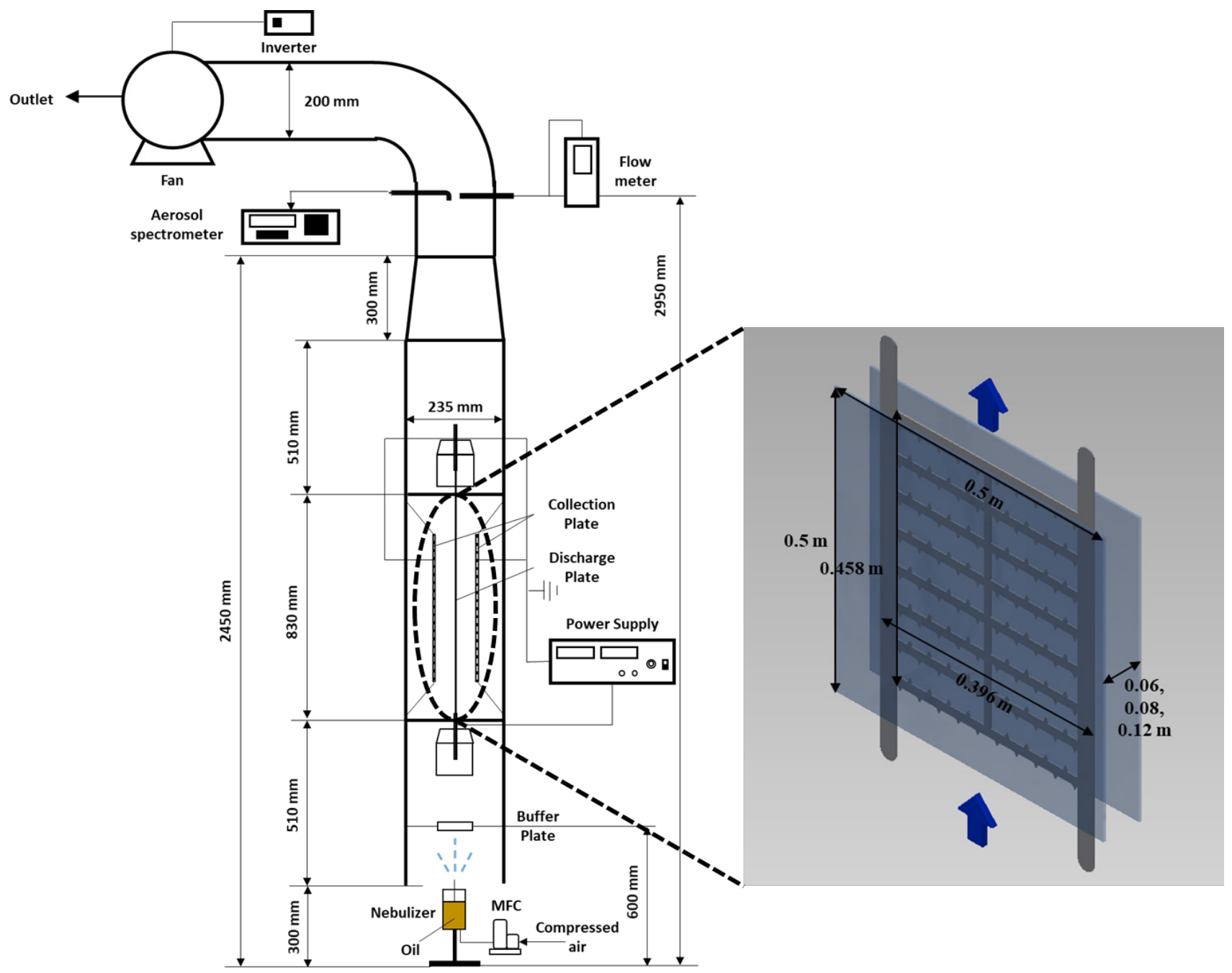

Fig. 1. Schematic diagram of the experimental apparatus.

reducing the supports for the discharge pins by one and maintaining equal spacing, the height of each support increased to $15,25,35,52$, and $76 \mathrm{~mm}$.

\section{RESULTS AND DISCUSSION}

\section{Comparison of Particle Removal Efficiencies with Variations in Flow Rate}

Changes in oil mist removal with variations in flow rate were measured using a discharge electrode with the basic features shown in Fig. 2, with the gap between collection plates fixed at $60 \mathrm{~mm}$. To calculate the oil mist removal efficiency, the mass concentration downstream of the EME was measured with a portable laser aerosol spectrometer connected to an isokinetic sampling probe. As shown in Eq. (1), we compared the $\mathrm{PM}_{10}$ concentrations measured downstream of the EME that had voltages from -10 to $-14 \mathrm{kV}$ applied to the EME with $\mathrm{PM}_{10}$ concentrations measured downstream of the EME with no voltage applied.

$\eta=\left(1-\frac{C_{1}}{C_{0}}\right) \times 100[\%]$
In this case, $\mathrm{C}_{0}$ is the $\mathrm{PM}_{10}$ concentration of particles measured downstream of the EME when no voltage was applied to the EME, and $\mathrm{C}_{1}$ is the $\mathrm{PM}_{10}$ concentration downstream of the EME with voltage applied.

Fig. 4(a) shows the average distribution of mass concentration by particle size when no voltage was applied to the EME of oil mist removal efficiency with variations in the flow rate of a flat plate-type wet electrostatic precipitator. When oil particles smaller than $10 \mu \mathrm{m}$ were generated with the nebulizer, the highest concentration of particles was $122.8 \mu \mathrm{g} \mathrm{m}^{-3}$ at 2.5 to $3.0 \mu \mathrm{m}$ in size. The face velocity of the EME was increased from $2 \mathrm{~m} \mathrm{~s}^{-1}$ to $5 \mathrm{~m} \mathrm{~s}^{-1}$ in increments of $1 \mathrm{~m} \mathrm{~s}^{-1}$, and each experiment was conducted twice. When no voltage was applied to the EME, the average $\mathrm{PM}_{10}$ concentration was about $712.8 \mu \mathrm{g} \mathrm{m} \mathrm{m}^{-3}$, with a deviation of about $16.7 \mu \mathrm{g} \mathrm{m}^{-3}$. Fig. 4(b) shows the voltagecurrent characteristics of the oil mist removal efficiency experiment with flow rate, and indicates that the corona onset voltage was $-6.2 \mathrm{kV}$.

Fig. 4(c) shows the oil mist removal efficiency with variations in flow rate and in $\mathrm{PM}_{10}$ concentration. As the face velocity of EME was increased from $2 \mathrm{~m} \mathrm{~s}^{-1}$ in steps of 


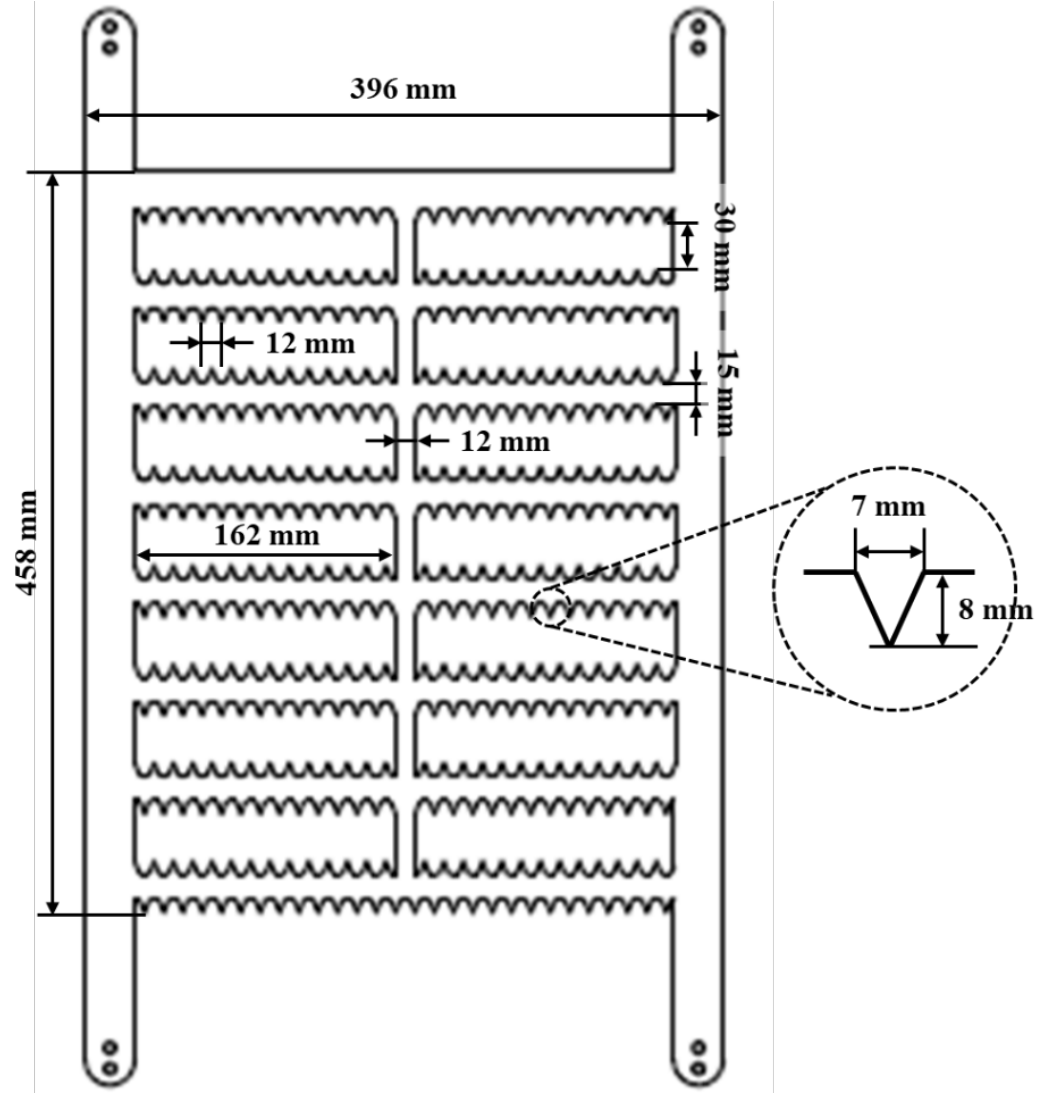

Fig. 2. General form of the discharge electrode.

[1] The variation of the horizontal distance between discharge pins

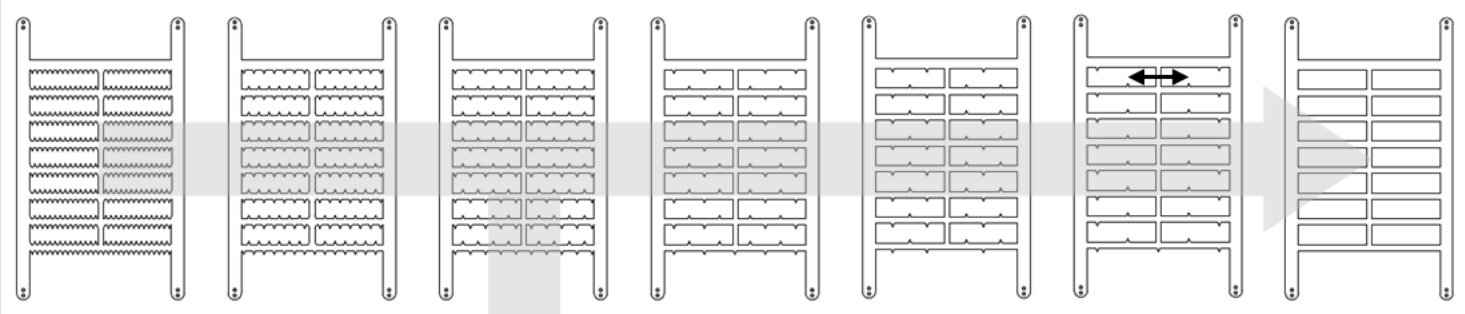

[2] The variation of the longitudinal distance between discharge pins
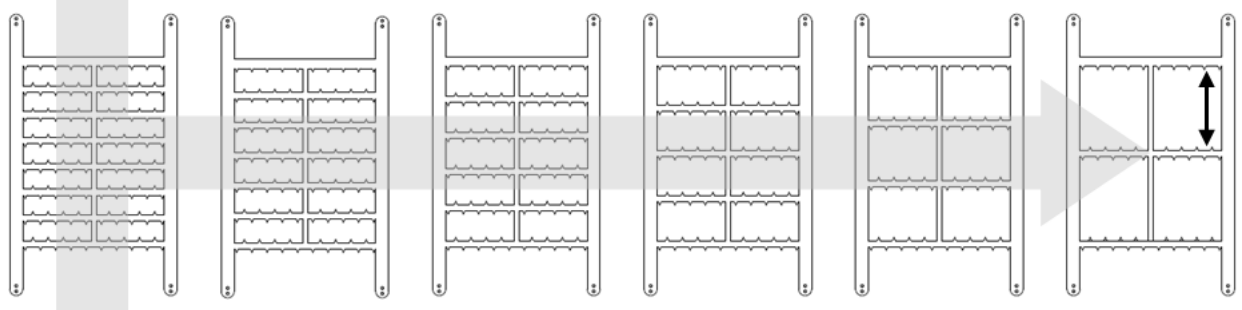

[3] The variation of the height of the discharge pin support
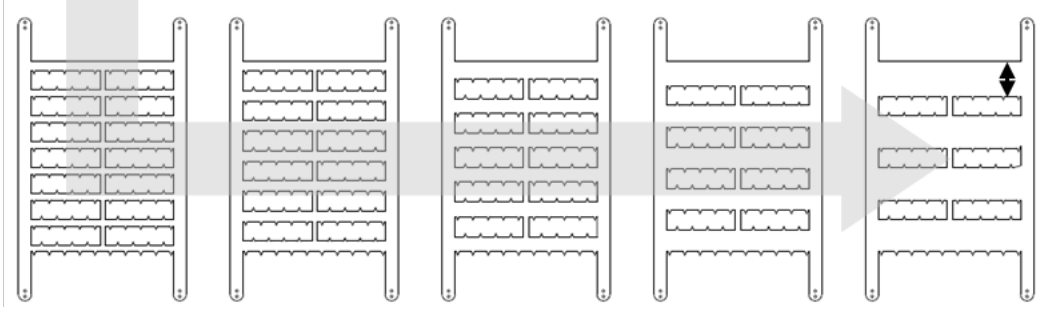

Fig. 3. Variations in the geometry of the discharge electrode for comparing particle removal efficiency. 


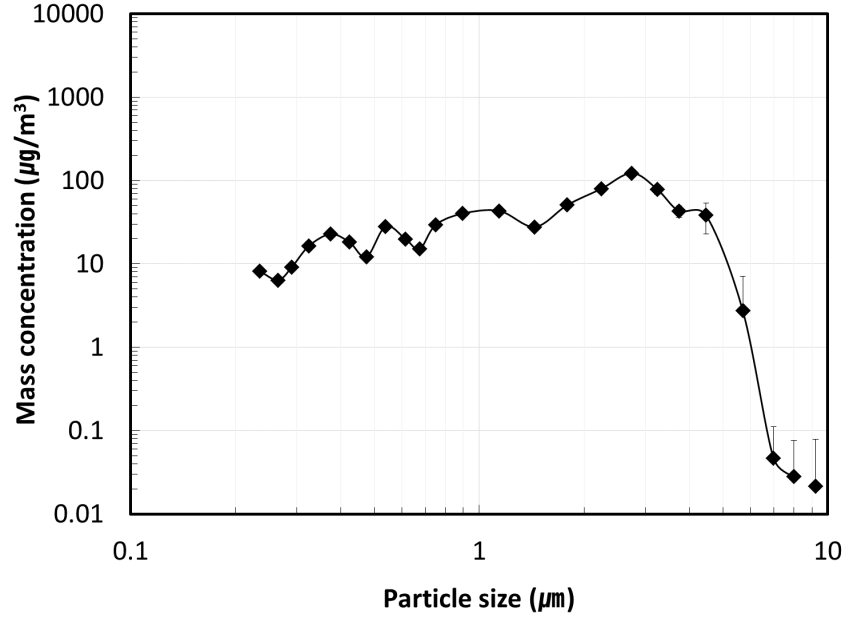

(a)

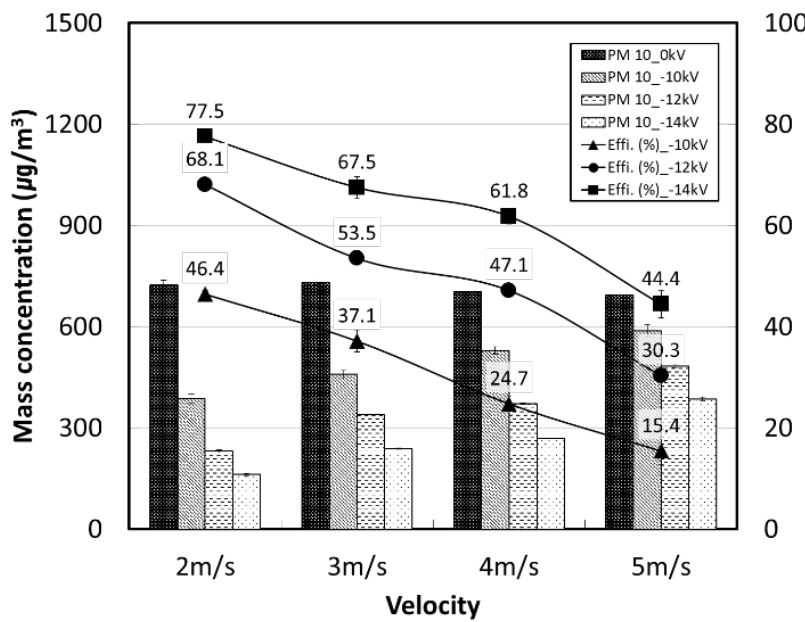

(c)

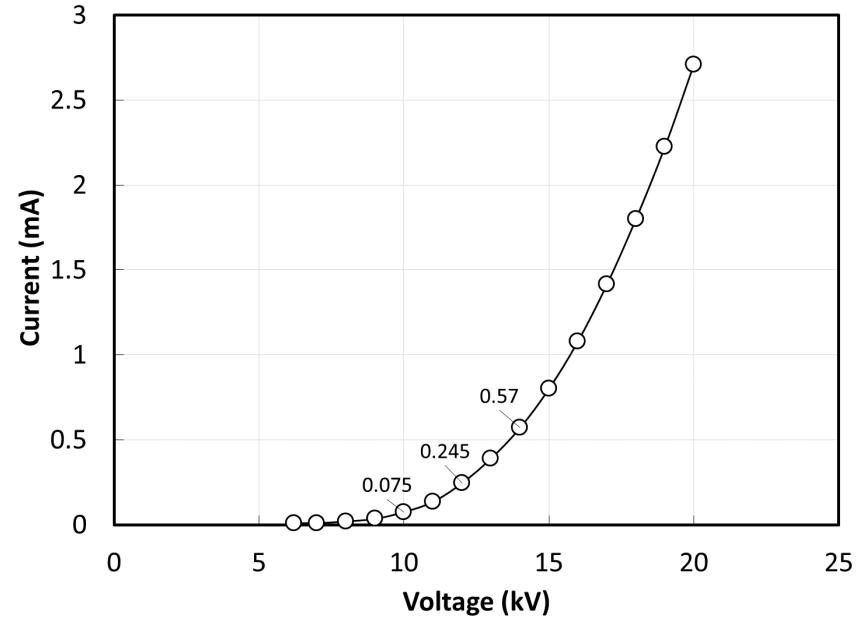

(b)

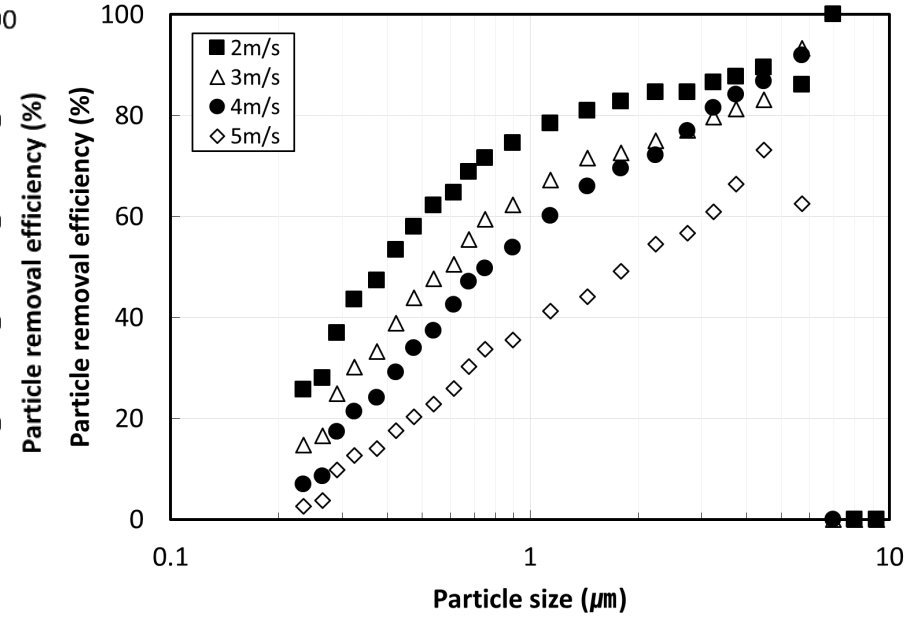

(d)

Fig. 4. Results of the particle removal efficiency experiment with variation in flow velocity. (a) Average upstream oil particle size distribution, (b) voltage-current (V-I) characteristics, and (c) downstream mass concentration and particle removal efficiency with variation in applied voltage, and (d) comparison of particle removal efficiency by particle size.

$1 \mathrm{~m} \mathrm{~s}^{-1}$, the particle removal efficiency generally decreased linearly. As shown in Eq. (2), the particle removal efficiency of an electrostatic precipitator is largely dependent on residence time (L/ $\left.v_{0}\right)$ (Mizuno, 2000). Thus, as the flow rate increases, the residence time of particles passing through the electric field decreases, causing the particle removal efficiency to also decrease, as indicated by Eq. (2):

$\eta=1-\exp \left(-\frac{\omega_{e} L K}{v_{0} b}\right)$

where $\omega_{\mathrm{e}}$ is the migration velocity of the particle $\left(\mathrm{m} \mathrm{s}^{-1}\right), \mathrm{L}$ is the length of the collection electrode along the gas stream $(\mathrm{m}), v_{0}$ is the gas velocity $\left(\mathrm{m} \mathrm{s}^{-1}\right), \mathrm{b}$ is the gap between the discharge and collection electrodes $(\mathrm{m})$, and $\mathrm{K}$ is a correction factor determined from the geometry of the electrodes to account for condensation and re-entrainment.

Fig. 4(d) shows the particle removal efficiency by particle size at various flow rates. As particle size increased, the particle removal efficiency tended to increase linearly. Particles larger than $3 \mu \mathrm{m}$ showed removal efficiencies of approximately $80.0 \%$ or greater under almost all face velocity conditions, including 2,3 , and $4 \mathrm{~m} \mathrm{~s}^{-1}$, but not $5 \mathrm{~m} \mathrm{~s}^{-1}$.

\section{Comparison of Particle Removal Efficiencies with Variation in the Gap between Collection Electrodes}

Evaluation of EME performance according to the gap between collection electrodes employed a discharge electrode with the basic features shown in Fig. 2, with the face velocity of the EME fixed at $4 \mathrm{~m} \mathrm{~s}^{-1}$ and the gap between the collection electrodes adjusted to 60,80 , and $120 \mathrm{~mm}$ for the comparative experiment. The general ESP was designed for a face velocity of around $1 \mathrm{~m} \mathrm{~s}^{-1}$, but when the face velocity of the ESP is $4 \mathrm{~m} \mathrm{~s}^{-1}$ and the amount of gas processed is equal, the size of the ESP can be reduced to one-quarter of its original size; therefore, the experiment was conducted using a face velocity of $4 \mathrm{~m} \mathrm{~s}^{-1}$. When no voltage was applied to the EME, the average distribution of mass concentration by particle size showed a similar distribution to the oil mist 
removal experiment when flow velocity was varied, and the particle removal efficiency was derived as shown in Eq. (1).

Fig. 5(a) shows the voltage-current characteristics of the oil mist removal efficiency experiment with variation in the gap between collection electrodes. When the face velocity of the EME was $4 \mathrm{~m} \mathrm{~s}^{-1}$, voltages from 0 to $-28 \mathrm{kV}$ were applied to the EME using a high voltage generator to verify the current. The lowest corona onset voltage was $-6.35 \mathrm{kV}$ when the gap between collection electrodes was $80 \mathrm{~mm}$, and the corona onset voltages were $-6.6 \mathrm{kV}$ and $-7.0 \mathrm{kV}$ when the gap was $120 \mathrm{~mm}$ and $60 \mathrm{~mm}$, respectively. The narrower the gap between collection electrodes, the stronger the current generated from the same voltage applied to the EME. Because the strength of the electric field was inversely proportional to the gap between collection electrodes, applying the same voltage resulted in a lower particle removal efficiency as the gap between collection electrodes increased. Particle removal efficiencies were compared at the same power consumption per unit flow rate $\left(\mathrm{W}\left(\mathrm{m}^{3} \mathrm{~min}^{-1}\right)^{-1}\right)$, determined according to the gap between collection electrodes, with equal face velocities of the EME, as described by Eq. (3):

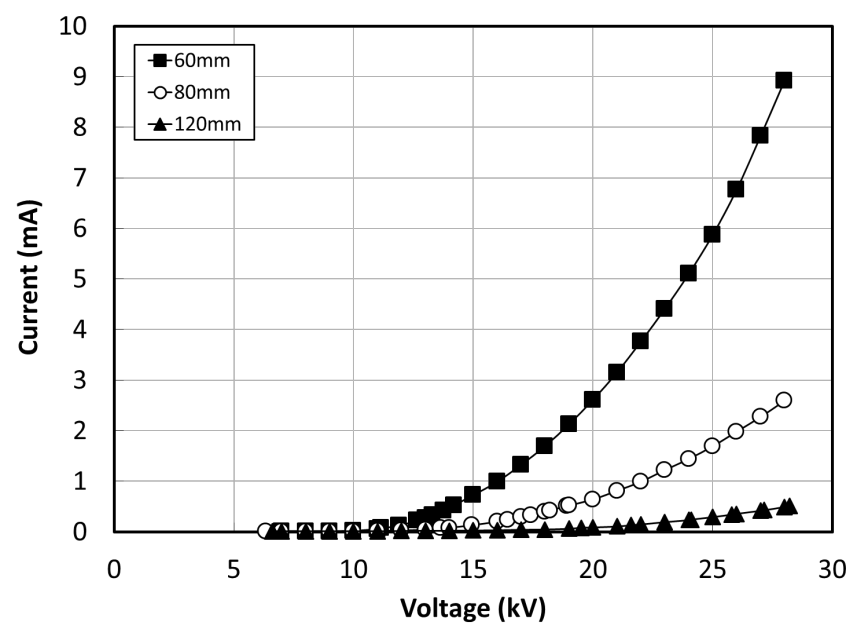

(a)

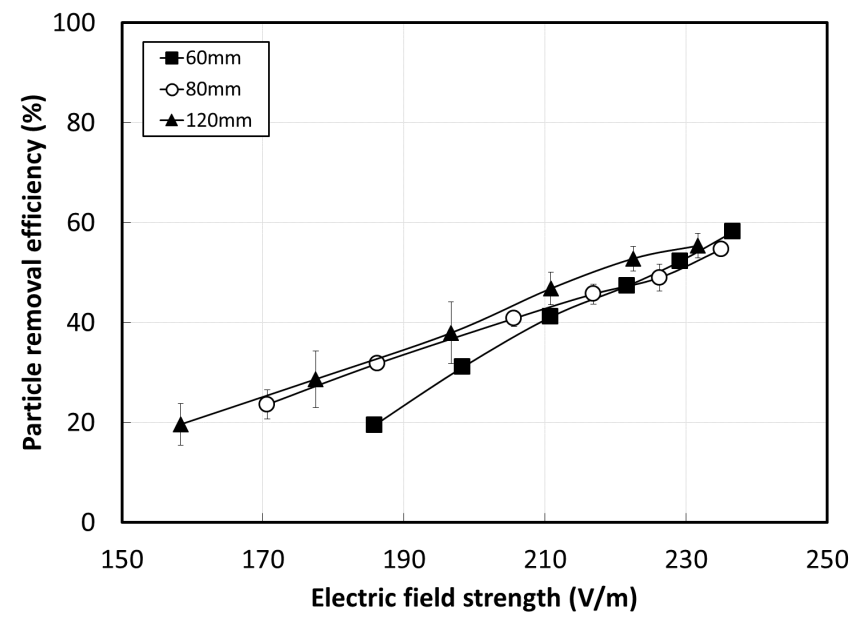

(c) $\eta=1-\exp \left(\frac{\omega A}{Q}\right)=1-\exp \left(\frac{q E A}{3 \pi \mu d_{p} Q}\right), \omega=\frac{q E}{3 \pi \mu d_{p}}$

where $\omega$ is the migration velocity of the particle $\left(\mathrm{m} \mathrm{s}^{-1}\right), \mathrm{A}$ is the collection area $\left(\mathrm{m}^{2}\right), \mathrm{Q}$ is the flow rate $\left(\mathrm{m}^{3} \mathrm{~s}^{-1}\right), \mathrm{q}$ is the particle charge $(\mathrm{C}), \mathrm{E}$ is the intensity of the electric field $\left(\mathrm{V} \mathrm{m}^{-1}\right), \mu$ is the viscosity of raw gas $(\mathrm{Pa} \cdot \mathrm{s})$, and $\mathrm{d}_{\mathrm{p}}$ is the diameter of the particle (m). According to Eq. (3) (Mizuno, 2000), given the same flow rate of the EME, an increase in the clearance of the collection electrodes will increase the flow rate of the gas, and therefore a higher voltage should be applied to the EME. Various voltages were applied with various collection electrode clearances to compare particle removal efficiencies at $0.1,0.2,0.4,0.6,0.8$, and $1.0 \mathrm{~W}\left(\mathrm{~m}^{3} \mathrm{~min}^{-1}\right)^{-1}$, but the currents were similar at the same power consumption per unit flow rate. Fig. 5(b) shows particle removal efficiencies according to power consumption per unit flow rate, which were nearly identical with various clearances of the collection electrodes. Fig. 5(c) shows particle removal efficiencies according to electric field strength and clearance of the

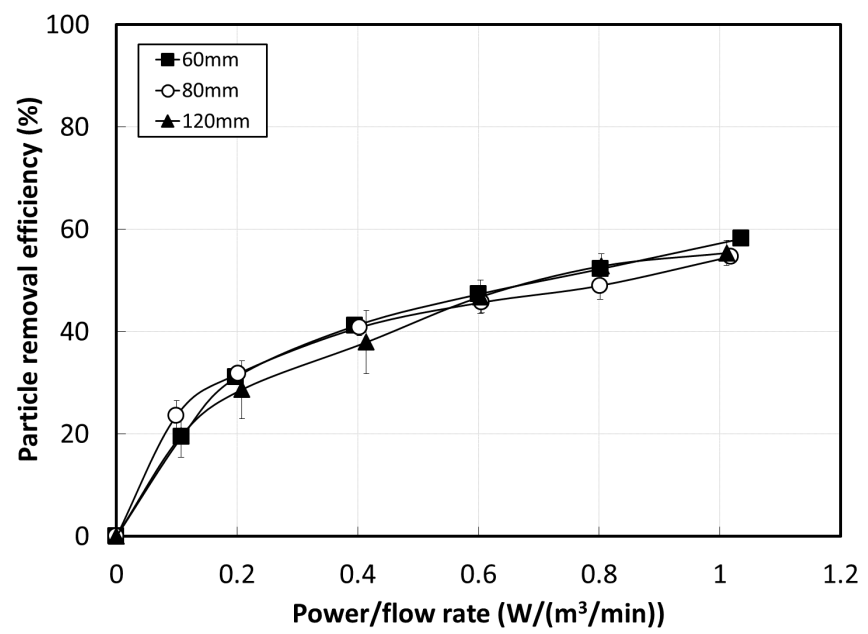

(b)

Fig. 5. Results of the particle removal efficiency experiment with variations in the gap between collection plates: (a) V-I characteristics, particle removal efficiency (b) by power/flow rate, and (c) by electric field strength. 
collection electrodes. When the particle removal efficiency was about $20 \%$, the electric field strength varied, but it was nearly constant at about $60 \%$ removal efficiency. However, when the clearance of the collection electrodes was narrow, a low capacity DC power supply could be used to achieve stable corona discharge. Therefore, in this study, a collection electrode clearance of $60 \mathrm{~mm}$ was used for comparing various discharge electrode shapes.

\section{Comparison of Particle Removal Efficiencies with Various Discharge Electrode Shapes}

Fig. 6(a) shows the voltage-current characteristics with various horizontal distances between the discharge pins. At $4 \mathrm{~m} \mathrm{~s}^{-1}$, the current was checked by applying voltage of 0 to $-20 \mathrm{kV}$ to the EME. The lowest corona onset voltage was $-6.2 \mathrm{kV}$ when the horizontal distance between the discharge pins was $12 \mathrm{~mm}$, and corona discharge was initiated at $-7 \mathrm{kV}$ for the discharge electrode without discharge pins. Horizontal distances between discharge pins of 12,24 , and $36 \mathrm{~mm}$ showed similar voltage-current characteristics, and the current gradually decreased with the same voltage applied in the order of 72,81 , and $144 \mathrm{~mm}$, and the electrode without discharge pins. This indicates that even when the number of discharge pins was reduced as horizontal distances between the discharge pins increased to 12,24 , and $36 \mathrm{~mm}$, the electric field overlay between adjacent discharge pins had similar corona discharge characteristics, whereas for distances of $72 \mathrm{~mm}$ or more, the electric fields of the discharge pins became independent of each other, resulting in significant reduction of the corona discharge current. Fig. 6(b) shows the $\mathrm{PM}_{10}$ and $\mathrm{PM}_{2.5}$ removal efficiencies with $-14 \mathrm{kV}$ applied at various horizontal distances between discharge pins. With the same voltage applied, horizontal distances of 12, 24, 36, and $72 \mathrm{~mm}$ with approximately same current showed similar particle removal efficiencies. The particle removal efficiency decreased in the order of $81 \mathrm{~mm}, 144 \mathrm{~mm}$, and no discharge pins. The level of particle charging should be similar, as the current of the corona discharge pin increased to $36 \mathrm{~mm}$. Meanwhile, the current of the corona discharge decreased at larger intervals, thereby reducing particle charging and collection efficiency. Fig. 6(c) shows particle removal efficiencies by particle size as the horizontal distance

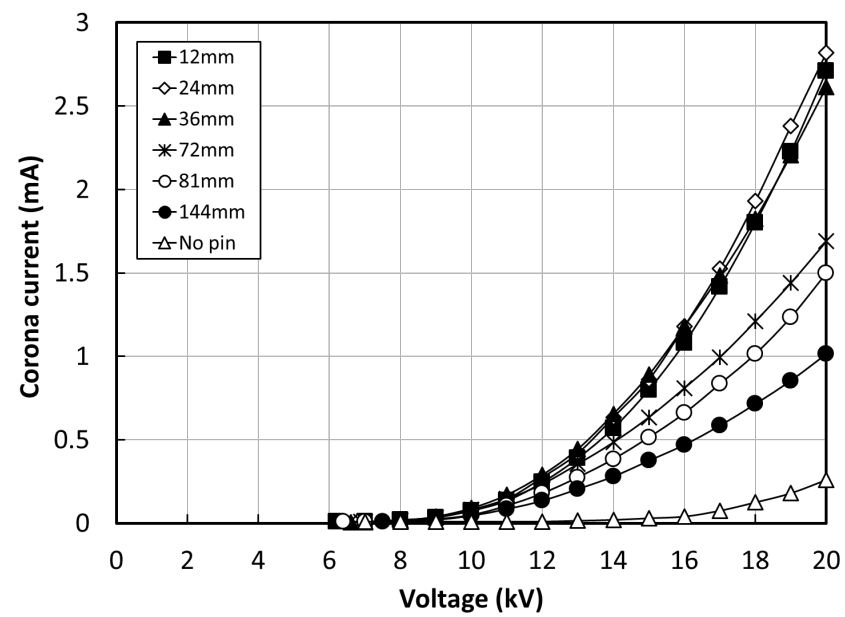

(a)

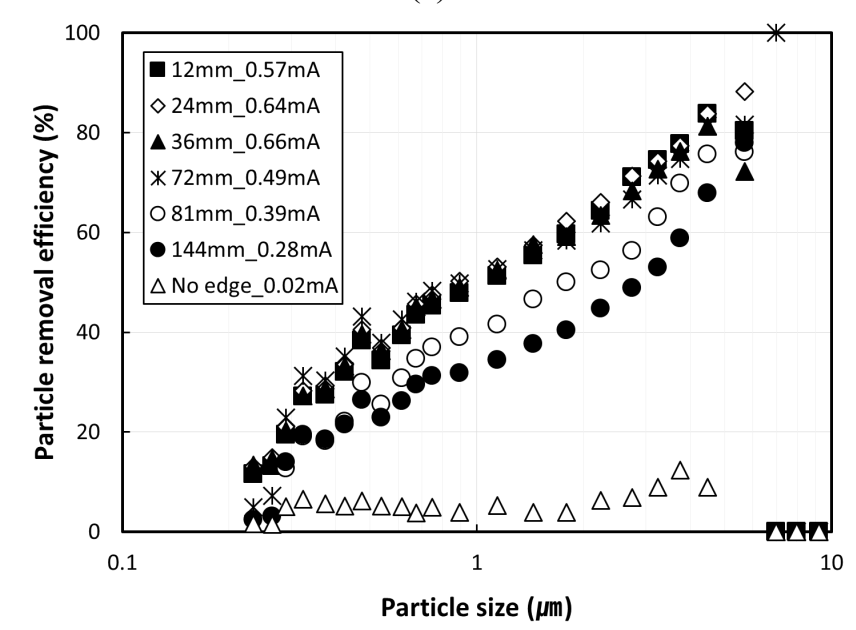

(c)

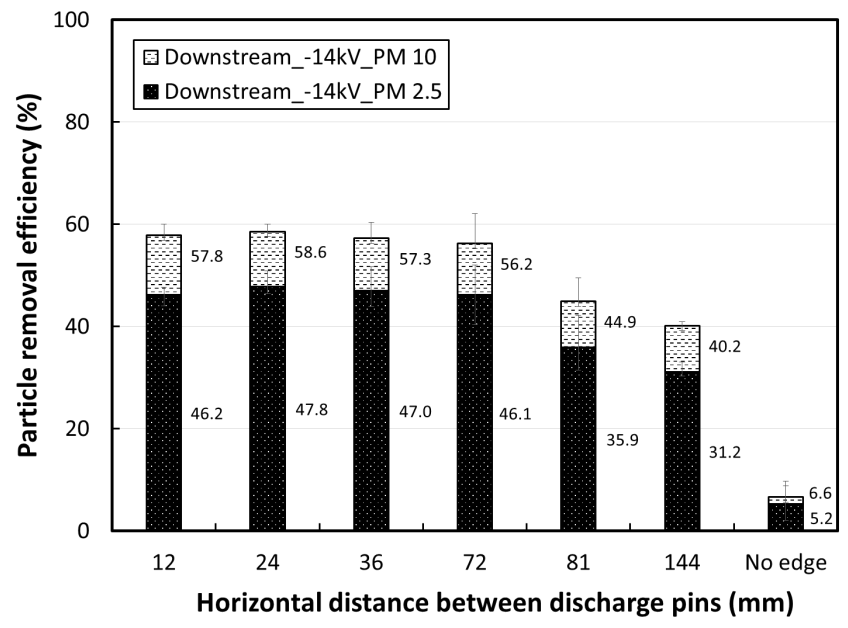

(b)

Fig. 6. Results of the particle removal efficiency experiment with variation in the horizontal distance between discharge pins: (a) V-I characteristics, particle removal efficiency (b) with variation in horizontal distances between discharge pins, and (c) by particle size. 
between discharge pins was varied. The particle charge level is proportional to $d_{p}{ }^{2}$ for field charging and $d_{p}$ for diffusion charging. Thus, as particle size increases, particle removal efficiency also increases. When $-14 \mathrm{kV}$ was applied to the EME, even when the horizontal distance between discharge pins increased to $72 \mathrm{~mm}$, particle removal efficiencies were similar for all particle sizes. As the horizontal distance between discharge pins increased to 81 and $144 \mathrm{~mm}$, and in the version without discharge pins, particle removal efficiencies by particle size decreased gradually. Moreover, $80 \%$ or more of particles larger than $5 \mu \mathrm{m}$ were removed when the horizontal distance between discharge pins increased from 12 to 24,36 , and $72 \mathrm{~mm}$.

Fig. 7(a) shows the voltage-current characteristics with varying longitudinal distance between discharge pins. At $4 \mathrm{~m} \mathrm{~s}^{-1}$, the current was checked by applying voltages to the EME of 0 to $-20 \mathrm{kV}$. The lowest corona discharge onset voltage was $-5.4 \mathrm{kV}$ when the longitudinal distance between discharge pins was 76,111 , and $183 \mathrm{~mm}$. Discharge pins spaced at $30,40,54$, and $76 \mathrm{~mm}$ showed similar voltage-

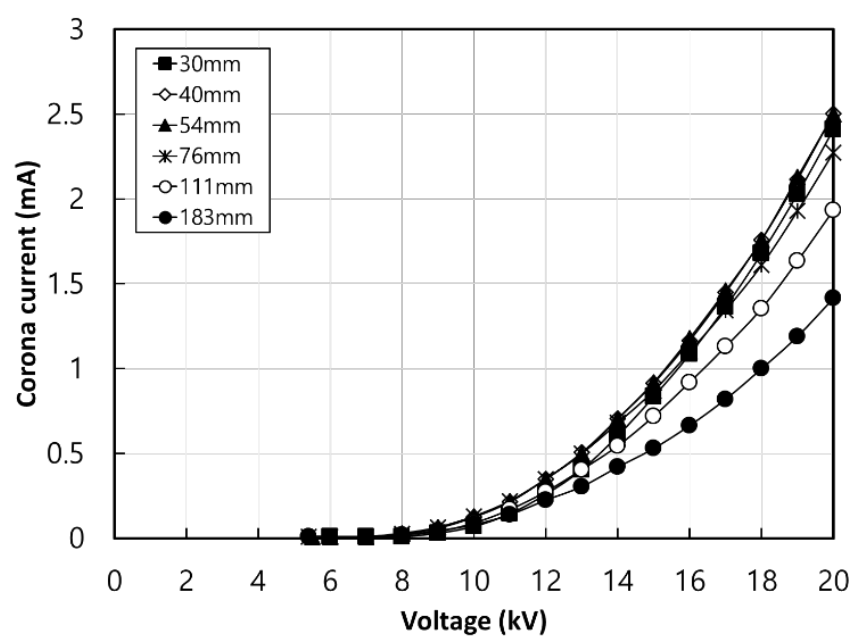

(a)

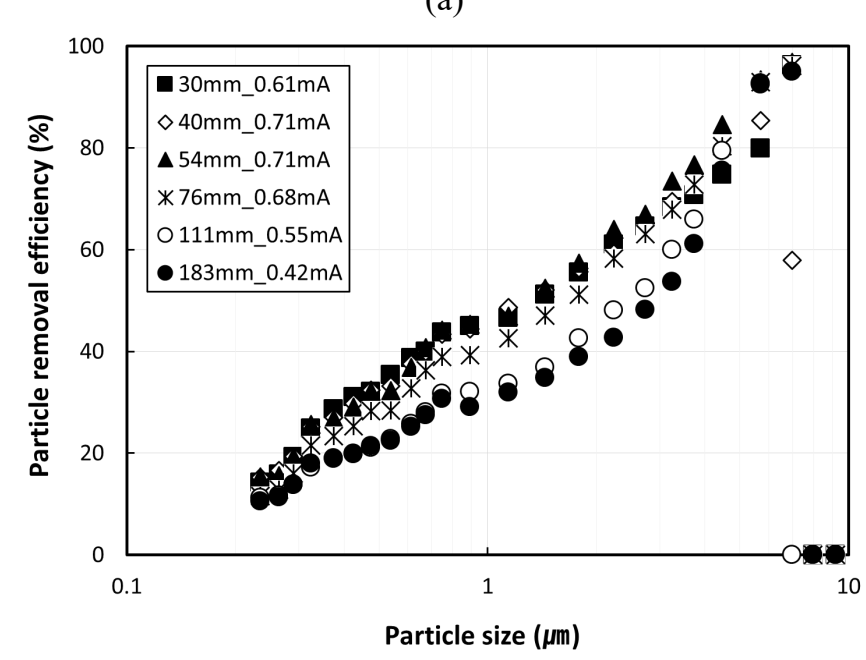

(c) current characteristics, with the current gradually decreasing at the same applied voltage from spacings of 111 to $183 \mathrm{~mm}$. This indicates that even as the number of discharge pins decreased with increasing longitudinal distances between discharge pins of 30,40,54, and $76 \mathrm{~mm}$, the electric field overlay between adjacent discharge pins led to similar corona discharge, whereas a distance of $111 \mathrm{~mm}$ between discharge pins caused the electric fields of the discharge pins to be independent, resulting in a significant reduction in the corona discharge current. Fig. 7(b) shows the $\mathrm{PM}_{10}$ and $\mathrm{PM}_{2.5}$ removal efficiencies when $-14 \mathrm{kV}$ is applied at various longitudinal spacings between discharge pins. With the same voltage applied, longitudinal distances of 30, 40, and $54 \mathrm{~mm}$, which have almost the same current, showed similar particle removal efficiencies. Particle removal efficiency decreased in the order of 76,111 , and $183 \mathrm{~mm}$. The particle charge should be similar as the current of the corona discharge pin increases up to $54 \mathrm{~mm}$. Meanwhile, the corona discharge current decreased in subsequent intervals, reducing the particle charge and thus the collection efficiency. Fig. 7(c)

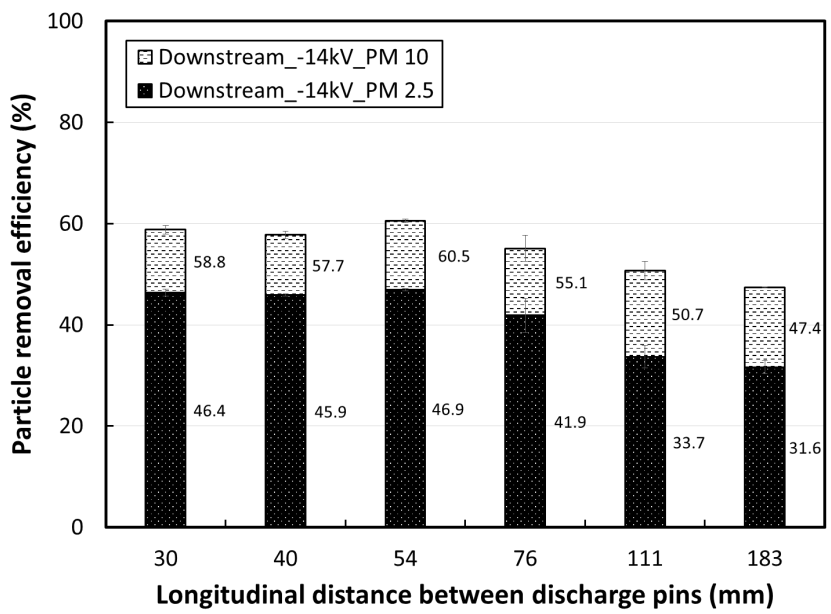

(b)

Fig. 7. Results of the particle removal efficiency experiment with variation in the longitudinal distance between discharge pins: (a) V-I characteristics, particle removal efficiency (b) with variation in longitudinal distance between discharge pins, and (c) by particle size. 
shows particle removal efficiencies by particle size with changes in the longitudinal spacing of the discharge pins. The particle charge level is proportional to $d_{p}^{2}$ for field charging and $d_{p}$ for diffusion charging. Thus, as the particle size increased, the particle removal efficiency also increased. When $-14 \mathrm{kV}$ was applied to the EME, even when the longitudinal distance between discharge pins increased to $54 \mathrm{~mm}$, the particle removal efficiencies by particle size were similar. As the longitudinal distance between discharge pins increased to 76,111 , and $183 \mathrm{~mm}$, the particle removal efficiencies by particle size decreased gradually. Moreover, $80 \%$ or more of particles larger than $5 \mu \mathrm{m}$ were removed with longitudinal spacings of the discharge pins up to $76 \mathrm{~mm}$.

Fig. 8(a) shows the voltage-current characteristics when the height of the discharge pin support was varied. At $4 \mathrm{~m} \mathrm{~s}^{-1}$, the current was determined by applying voltage to the EME of 0 to $-20 \mathrm{kV}$. The lowest corona onset voltage was -6.1 $\mathrm{kV}$ when the height of the discharge pin support was $25 \mathrm{~mm}$. Discharge pin heights of 15 and $25 \mathrm{~mm}$ showed similar voltage-current characteristics, and the current gradually decreased with the same applied voltage in the order of 35 , 52 , and $76 \mathrm{~mm}$. The corona discharge current likely decreased gradually because the number of discharge pins was reduced by one row. However, the voltage-current characteristics differed with changes in the longitudinal spacing of discharge pins and the height of the discharge pin support, despite equal reductions in the number of discharge pins. Further simulative analysis of electric field formation around the discharge electrodes is also needed. Fig. 8(b) shows the $\mathrm{PM}_{10}$ and $\mathrm{PM}_{2.5}$ removal efficiencies according to the height change of the discharge pin support when $-14 \mathrm{kV}$ was applied. As the number of serrated edges of discharge pins decreased, the current at high applied voltage was also expected to decrease. Thus, the strength of the electric field and the particle removal efficiency were also expected to fall. However, in contrast to the voltage-current characteristics, field strength and removal efficiency did not show apparent trends with the number of serrated edges. Although particle removal efficiency decreased when the longitudinal spacing of the discharge pins increased to $76 \mathrm{~mm}$ or more, increasing

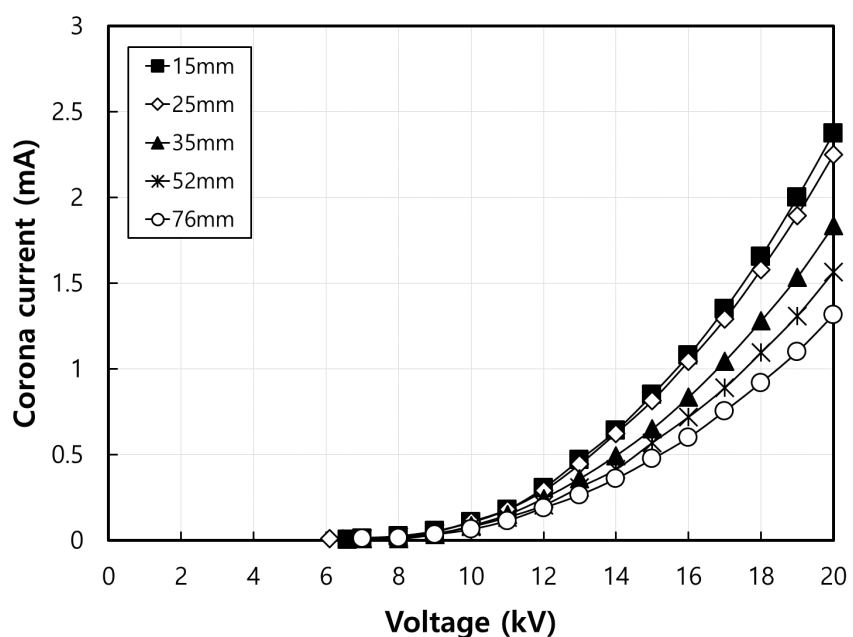

(a)

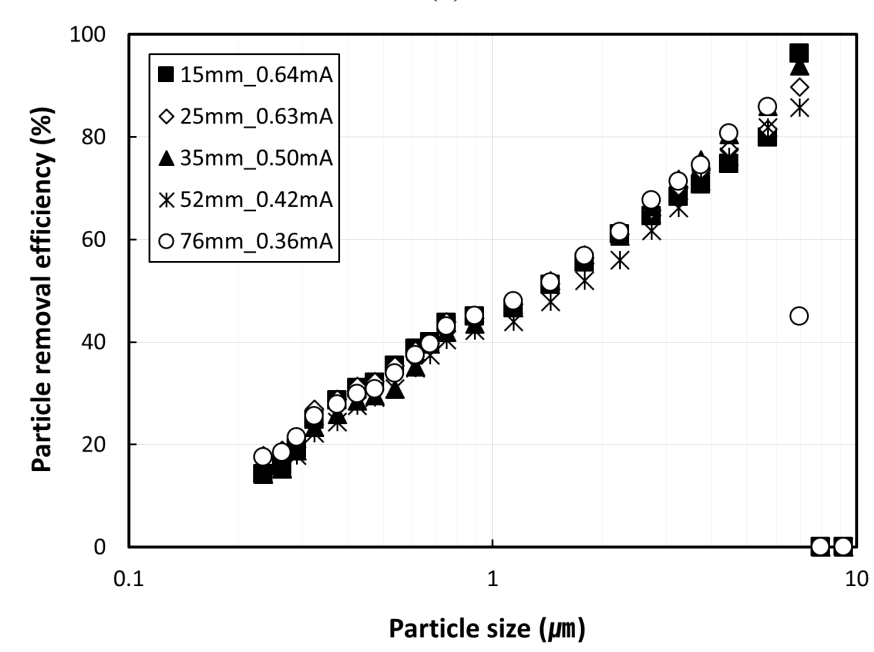

(c)

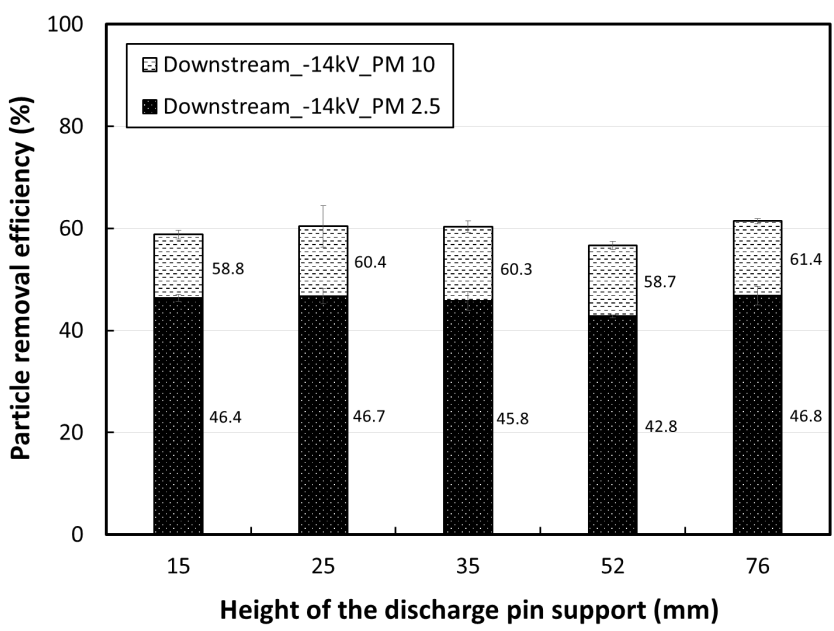

(b)

Fig. 8. Results of the particle removal efficiency experiment with variation in the height of the discharge pin support: (a) V-I characteristics, particle removal efficiency (b) with variation in the height of the discharge pin support, and (c) by particle size. 
the height of the discharge pin support and thus increasing the area of the electric field available to collect particles can offset the reduction caused by reducing the number of serrated edge-carrying rows of discharge pins. Future simulative analysis of electric field formation at the discharge electrodes is also needed. Fig. 8(c) shows particle removal efficiencies by particle size with changes in the height of the discharge pin support. The particle charge is proportional to $d_{p}^{2}$ for field charging and $d_{p}$ for diffusion charging. Thus, as the particle size increased, the particle removal efficiency also increased. When $-14 \mathrm{kV}$ was applied to the EME, the particle removal efficiencies by particle size were similar despite changes in the height of the discharge pin support. Furthermore, about $80 \%$ or more of particles larger than $5 \mu \mathrm{m}$ were removed when the height of the discharge pin support was 35 or $76 \mathrm{~mm}$.

\section{CONCLUSIONS}

This study introduces a new type of EME with plates combining a discharge electrode with the high voltage plate of the collection stage. This device produces more stable corona discharge compared to wire-type discharge electrodes. The form of the new EME is a single-stage electrostatic precipitator wherein charging and collection occur in the same space simultaneously. The flow rate of the EME developed in this study was $4 \mathrm{~m} \mathrm{~s}^{-1}$, whereas the flow rate of a modern conventional electrostatic precipitator is $1 \mathrm{~m} \mathrm{~s}^{-1}$, allowing the EME to be only one-quarter the size of a typical electrostatic precipitator. This size reduction will make it easier to use at existing sites with limited installation space.

The shape of the discharge electrode is directly related to the collection efficiency of an EME and was optimized under constant applied voltage conditions. This experiment confirmed that particle removal efficiency is maintained when the horizontal and longitudinal distances between discharge pins and the height of the discharge pin support are below threshold levels. Those spacings are considered important design factors for discharge electrode shape. When designing a multi-channel EME, the horizontal and longitudinal distances and height of the discharge pin support should be selected appropriately by considering the weight of discharge electrodes and processing costs.

\section{ACKNOWLEDGMENTS}

This work was supported by the Korea Institute of Energy Technology Evaluation and Planning (KETEP) and the Ministry of Trade, Industry \& Energy (MOTIE) of the Republic of Korea (No. 20161110100210), and also by the Basic Research Fund (NK212E) of the Korea Institute of Machinery and Materials.

\section{REFERENCES}

Azzopardi, B.J., Hughes, J.P., James, P.W. and Wang, W. (2003). The role of drainage channels in the performance of wave-plate mist eliminators. Chem. Eng. Res. Des. 81: 639-648.
Banitabaei, S.A., Rafee, R. and Rahimzadaeh. H. (2012). Determination of minimum pressure drop at different plate spacings and air velocity in a wave-plate mist eliminator. Asia-Pac. J. Chem. Eng. 7: 590-597.

Castanas, E. and Kampa, M. (2008). Human health effects of air pollution. Environ. Pollut. 151: 362-367.

Cho, M.H., Fang, G.C., Huang, C.Y., Tsai, K.H., Xiao, Y.F. and Zhuang, Y.J. (2018). Review of total suspended particles (TSP) and $\mathrm{PM}_{2.5}$ concentration variations in Asia during the years of 1998-2015. Environ. Geochem. Health 40: 1127-1144.

Choi, W. and Kim, J.J. (2018). Characteristics of ultrafine particles in urban areas observed worldwide and in Korea: Sources and emissions, spatial and temporal distributions, and health effects. Atmos. Korean Meteorol. Soc. 28: 337-355. (in Korean with English Abstract)

Czech, T., Jaworek, A., Krupa, A., Marchewicz, A. and Sobczyk, A.T. (2018). Two-stage electrostatic precipitators for the reduction of $\mathrm{PM}_{2.5}$ particle emission. Prog. Energy Combust. Sci. 67: 206-233.

Guerra, V.G. and Oliveira, A.E. (2018). Influence of particle concentration and residence time on the efficiency of nanoparticulate collection by electrostatic precipitation. $J$. Electrostat. 96: 1-9.

Hamedi Estakhrsar, M.H. and Rafee, R. (2016). Effects of wavelength and number of bends on the performance of zigzag demisters with drainage channels. Appl. Math. Modell. 40: 685-699.

James, P.W. and Wang, Y. (1998). The calculation of waveplate demister efficiencies using numerical simulation of the flow field and droplet motion. Chem. Eng. Res. Des. 76: 980-985.

Jiang, J., Liu, Y., Xu, M., Yao, H., Yu, D. and Yu, X. (2017). Experimental and numerical evaluation of the performance of a novel compound demister. Desalination 409: 115-127.

Jo, Y.M. and Park, H. (2013). Regulation standard of fine particles and control techniques of emission sources. $J$. Korean Soc. Atmos. Environ. 29: 486-503. (in Korean with English Abstract)

Kulasekharan, N., Iniyan, S. and Venkatesan, G. (2013). Influence of turbulence models on the performance prediction of flow through curved vane demisters. Desalination 329: 19-28.

Melaaen, M.C. and Jøsang, A.I. (2002). Fluid flow simulations of a vane separator. Model. Identif. Control 23: 5-26.

Mizuno, A. (2000). Electrostatic precipitation. IEEE Trans. Dielectr. Electr. Insul. 7: 615-624.

Yuan, S., Fan, Y. and Lin, H. (2016). Influence of discrete particle diameter and separating velocity on the separation efficiency of wave-plate separator including coalescence and breakup model. J. Dispersion Sci. Technol. 37: 13241333.

Received for review, December 22, 2019 Revised, December 22, 2019 Accepted, January 30, 2020 